\title{
Hypopharyngeal Carcinoma
}

National Cancer Institute

\section{Source}

National Cancer Institute. Hypopharyngeal Carcinoma. NCI Thesaurus. Code C9465.

Carcinoma, predominantly squamous cell, arising from the epithelial cells of the hypopharynx. 